\title{
Merger and Reorganization to Promote Industrial Upgrading: Review and Prospect of Research
}

\author{
Xiaolin Sun ${ }^{\mathrm{a}}$, Dongyang Cao ${ }^{\mathrm{b}}$ \\ School of management, Dalian polytechnic University, Dalian 116000, China; \\ axlsun_dlpu@126.com, ${ }^{b} 1063593002 @ q q . c o m$
}

Keywords: industrial upgrading, mergers and acquisitions, research reviews.

\begin{abstract}
In recent years, with the economic restructuring in our country, the traditional mode of development has not adapted to the rapid economic growth. As the key to economic restructuring and upgrading, industrial upgrading has become an inevitable choice for Chinese enterprises to achieve industrial development. However, $\mathrm{M} \& \mathrm{~A}$ can optimize the allocation of resources among regions and further promote industrial upgrading and optimization. Based on the viewpoints of $M \& A$, this paper reviews and summarizes the related research results of $\mathrm{M} \& \mathrm{~A}$ and industrial upgrading in recent years on the basis of literature review, explores the mechanism and impact of $\mathrm{M} \& \mathrm{~A}$ on industrial upgrading, and analyzes the relationship between $\mathrm{M} \& \mathrm{~A}$ and industry looking forward to the further study of escalation.
\end{abstract}

\section{Introduction}

As an important way for Chinese enterprises to achieve rapid expansion, $\mathrm{M} \& \mathrm{~A}$ and restructuring are more and more favored by listed companies. With the continuous development and improvement of the $\mathrm{M} \& \mathrm{~A}$ market, new modes of $\mathrm{M} \& \mathrm{~A}$, such as multinational mergers and acquisitions, mergers and acquisitions by foreign investors, and cross-regional mergers and acquisitions within a country, have been booming in the M \& A market one after another. Cross-regional mergers and acquisitions can not only meet the enterprise's goal of optimizing the allocation of resources and improving the level of corporate governance, but also promote the optimization and upgrading of the inter-regional industrial structure through the flow of resources between regions, thereby promoting economic restructuring. On the basis of cross-regional mergers and acquisitions, cross-border mergers and acquisitions also bring about positive corporate governance spillover effects due to differences in corporate governance due to the differences in culture and systems among different countries.

In 2014, our country entered a new economic normal. The new normal economy is the economy with a steady growth of the structural adjustment, with a view to the symmetry of the economic structure and the sustainable development based on symmetry. Therefore, the traditional pattern of high energy consumption and uncoordinated economic development has gradually been replaced. In the critical period of economic restructuring, industrial upgrading is particularly important. To a certain extent, the readjustment and upgrading of the industrial structure are conducive to the sustained and steady growth of the national economy in our country and boosting the supply-side structural reform. With the transformation and upgrading of the industrial structure, mergers and acquisitions are more and more important. $\mathrm{M} \& \mathrm{~A}$ and reorganization promote the spatial transfer of resources, on the one hand, to increase industry concentration and enable resources to gather with superior enterprises; on the other hand, to speed up the integration of technology and resources of high-tech industries and traditional industries, promote the development of traditional industries and further promote the industrial structure Upgrade. Based on the research of related literatures, this paper systematically combs the definition and measurement of industrial upgrading by domestic and foreign scholars, and explores its mechanism and impact on industrial upgrading from the perspective of mergers and acquisitions, and finally deepens the $\mathrm{M} \& \mathrm{~A}$ and industrial upgrading. The research has made a prospect. 


\section{Definition and Measurement of Industrial Upgrading}

\subsection{The Concept of Industrial Upgrading.}

On the definition of the concept of industrial upgrading, foreign literature mostly based on the perspective of the global value chain. In addition to the domestic reference to the definition of the value chain, most tend to adjust the industrial structure. In the late 1990s, with the introduction of the concept of global value chain into industrial upgrading, the definition of industrial upgrading gradually translated into the industry's rising process from low-end to high-end in the global value chain. Based on the perspective of value chain, the study on the structural transformation and upgrading of various industries can be traced back to Porter's value chain analysis model. Based on the value chain model, he studies the industrial upgrading of manufacturing industry with the change of product added value and technological innovation; that competition is not only between enterprises, but also the competition between the value chains. Knout (1985) put forward the value chain fragmentation theory, believing that each link in the value chain should be deployed within the global space. All countries go beyond national borders and carry out value-added activities in different stages according to their own advantages so as to achieve optimal resources Configure [1]. Giraffe (1999) extended the concept of value chain and applied it to the international division of labor. He proposed the global chain theory of goods that the global production network formed by the goods and services from production to eventual recycling, and played by countries in the production process Different roles [2]. Based on previous studies, Poon (2004) proposed that industrial upgrading is the process of value transformation from low-value labor-intensive products to high-value technology-intensive products [3].

The domestic research on industrial upgrading first appeared in Yang HI's "Introduction to Industrial Economics", and for the first time in the country put forward the western theory of industrial structure. In recent years, with the introduction of the concept of global value chain, more and more domestic scholars have turned to define the industrial upgrading from the perspective of value chain. Wang Bolin (2009) refers to Giraffe's theory of industrial upgrading and defines industrial upgrading as the process of resource reallocation within the same industry or between different industries [4]. Feng Shaun et al. (2016) pointed out that industrial upgrading is the process of rising from the low-value part to the high-value part of the value chain and divides the industrial upgrading into two forms: first, in the process of industrial development, from the original raw material itself Based development model has shifted to focusing on the development of deep processing of raw materials and assembly technology. The second is the refinement of the division of labor within the industry, from low value-added links in the industrial value chain to high value-added links [5]. Bay Xenia and Wei Jingling (2017) quoted Wang Bolin's view that industrial upgrading is regarded as the trend and process of the industry evolving from a low-tech level and a low value-added state to a high-tech and high value-added state [6].

\subsection{The Measure of Industrial Upgrading.}

In the empirical study of previous scholars, the measurement of industrial upgrading mainly focused on macro and micro aspects. In the research based on macro perspective, most of them focus on the adjustment, development and changes of the national industrial structure. Measurements in this area date back to the "Standard Structure of Industrial Structure" by Chancery (1975), the "standard structure" of Kuznets. Huang and Chen (2007) used the ratio of the output value of the secondary industry to the total output value to measure the industrial structure change in the central region of China [7]. Li Yan (2009) studies the dynamic changes of industrial structure by constructing a single structure dynamic model, and uses the industrial structure component coefficients to reflect the advantages and disadvantages of industrial structure. If the coefficient is greater than zero, the industry is in a dominant position. If it is less than Zero, then at a disadvantage [8]. Wang Lego, Zhao Wash (2015), Zhou Xiao and Ago Men et al. (2015) adopted the relationship between the output value of the second and third industries to measure the upgrading of industrial structure [9-10]. YAN Dong and CHEN Neng-jun (2016) improved to measure the industrial upgrading by using the ratio of the 
added value of the tertiary industry to the GDP and the ratio of the added value of the secondary industry to the GDP. The larger this ratio is, the better the industrial structure is.

The indicators of industrial upgrading based on the medium and micro perspectives mainly include product added value, labor productivity, total profits and taxes, and industrial added value rate. Bay Xenia and Wei Jing (2017) used industry-based data to measure industrial upgrading using R \& D intensity and human capital intensity [11]. Wei Jing (2017) uses business data to measure industrial upgrading using labor productivity [12]. Feng Shaun and Chen Wei (2015) refer to the contribution value proposed by the U.S. management scientist Peter Drucker to measure the added value of products, and measure the industrial upgrading based on the proportion of total profits [13].

\section{The Impact of Mergers and Acquisition son Industrial Upgrading}

Enterprises through mergers and acquisitions to complete the integration of resources, to achieve the re-allocation of assets, so that after the merger and acquisition activities have a synergistic effect on resources, and this effect has potential benefits for the community as a whole. With the continuous development and improvement of the $\mathrm{M} \& \mathrm{~A}$ market, $\mathrm{M} \& \mathrm{~A}$ methods also show great differences. The common types of $\mathrm{M} \& \mathrm{~A}$ include horizontal mergers and acquisitions, vertical mergers and acquisitions, diversified strategies and the listing of stocks. Because of the differences between the host party and the target location, they can be divided into on-site acquisition, cross-border M \& A and cross-border $\mathrm{M} \& \mathrm{~A}$. Cross-border mergers and acquisitions involve two or more countries, through the loans of financial institutions, stock swap, bond issuance and other ways to obtain the target company's equity. Under the trend of economic globalization, cross-border mergers and acquisitions ( $M$ \& A) have been increasing year by year. Compared with mergers and acquisitions within one country, due to the huge differences in culture and political system among countries, obstacles to the implementation and integration process are brought about. Meanwhile, Mergers and acquisitions can better exert the spillover effect of corporate governance and produce expected merger and acquisition effects. Cross-regional $\mathrm{M} \& \mathrm{~A}$ takes place within one country and merges and acquisitions between different regions. Similar to cross-border M \& A, cross-regional M \& A can exert the spillover effect of corporate governance and increase the allocation efficiency of resources among industries through the spatial movement of resources to promote the inter-regional industrial structure Of the optimization and upgrading, boost China's economic restructuring and supply-side structural reforms.

\subsection{The Mechanism of $M$ \& $A$ and Restructuring on Industrial Upgrading.}

Scholars have carried out relevant research on the relationship between M \& A and industrial upgrading. Most studies show that M \& A can improve the allocation efficiency of resources among industries by spatial movement of resources and further promote the optimization and upgrading of industrial structure in our region and accelerate the process of industrial upgrading. The mechanism of $\mathrm{M} \& \mathrm{~A}$ and reorganization on industrial upgrading can be explained from two aspects: one is based on value chain and the other is on the basis of industrial transfer.

The most widely used definition of industrial upgrading is the global value chain theory. The concept of "value chain" originates from Michael E. Porter's (1985) theory of competitive advantage. After many improvements by domestic and foreign scholars and the introduction of industrial upgrading, defined industrial upgrading as the process of rising from the low-value part of the industrial value chain to the high-value part. The "smile curve" proposed based on the perspective of the value chain, as shown in Figure 1, depicts the industrial upgrading more specifically. He believes that the industrial upgrading is a process in which the middle-level manufacturing link with low technology and low added value Added value, high-tech upstream R \& D and downstream marketing aspects of the climb. By acquiring the resources, technologies and advanced management methods of the target company through mergers and acquisitions, the enterprise integrates the factors conducive to the development of the enterprise with itself and promotes the moving of the enterprise products to 
both ends of the high value-added and high-tech industries. The continuous upgrading of enterprises to achieve the transformation and upgrading.

Industrial transfer is an important economic phenomenon that transfers part or all of the production of products from the original place of production to other areas and occurs in areas of different levels of economic development. Industrial transfer can optimize the allocation of resources through the spatial movement of capital and technology, which is a great impetus for the optimization and upgrading of the industrial structure between regions. There is a certain inherent relationship between industrial transfer and industrial upgrading. Marcuse and Enables, Zhou and others believe that industrial transfer can promote industrial upgrading on both sides of the industrial transfer, mainly in the form of industrial competition, specialized division of labor and technology transfer. As a unique form of industrial transfer, mergers and acquisitions ( $M \& A$ ), as a unique form of industrial transfer, have similar pathways to industrial upgrading. That is, $M \&$ As can increase the allocation efficiency of resources among industries through the flow of resources between target enterprises and main parties, thereby promoting the transformation and upgrading of industrial structure.

Additional value

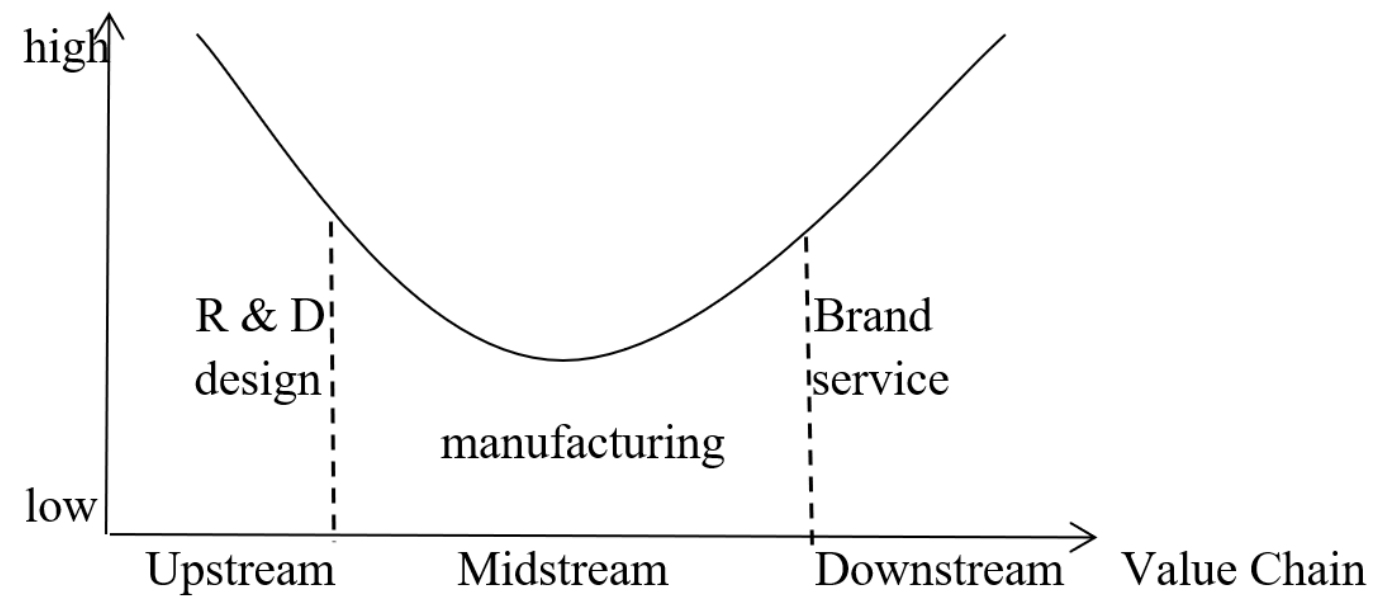

Fig. 1 smile curve

\subsection{Effects of Mergers and Acquisitions on Industrial Upgrading.}

Merger and reorganization, as an important way for enterprises to achieve scale expansion and strategic development, can not only improve the efficiency of resource allocation, but also play an important role in promoting economic development and upgrading of industrial structure. In the study of the relationship between mergers and acquisitions and industrial upgrading, most of the empirical studies are based on the perspective of cross-border mergers and acquisitions and cross-regional mergers and acquisitions in one country to study the impact of industrial mergers and acquisitions on industrial upgrading, The conclusion of the study concludes that mergers and acquisitions can play a positive role in promoting industrial upgrading.

Foreign literature there is no lack of research on mergers and acquisitions and industrial upgrading, and prefer to analyze the effect of cross-border M \& A on both sides of the target countries and M \& A countries. Eduardo Pablo (2009) analyzes the determinants of cross-border mergers and acquisitions in Latin America from 1998 to 2004 and points out that not only the economic and commercial environment of the target countries but also the mercantile business environment of mergers and acquisitions such as intellectual property protection will affect the occurrence of cross-border M \& A This, in turn, will affect industrial upgrading in the M\&A process [14]. Deified et al. (2010) applied the MNE (Foreign Multinationals) data set and took Italy as an example. The results show that the industries that the industry undertakes can easily promote the industrial upgrading through technical diffusion and technological spillover effects, thereby promoting industrial upgrading [15]. On the other hand, due to the inherent relationship between industrial transfer and industrial upgrading, some scholars also analyze industrial upgrading from the perspective of industrial transfer. Cross-regional M \& A can achieve industrial transfer through the spatial movement of stock capital. Dunning (1988) 
found that cross-border $\mathrm{M} \& \mathrm{~A}$ has more advantages in promoting industrial upgrading than other forms of investment, namely, the upgrading effect on the local industrial structure is more Obviously [16].

Domestic literature on mergers and acquisitions and industrial upgrading mostly focus on cross-regional mergers and acquisitions point of view, that is, mergers and acquisitions within different regions within a country. Mergers and acquisitions can cause the flow of resources in the enterprise, and cross-regional mergers and acquisitions will cause resources in the inter-regional flows. The flow of resources between regions can change the types of resources in the region and continuously improve the resource composition of the regions, thus causing changes in the industrial structure in the region and promoting the industrial upgrading and economic growth in the region. Bay Xenia and Wei Jingling (2017) after research, cross-regional mergers and acquisitions can promote the industrial upgrading of the mergers and acquisitions, but have no significant impact on the industrial upgrading of the merged land [6]. Hu et al. (2012) conducted an empirical test on cross-regional mergers and acquisitions of enterprises in seven regions including North China, East China and South Africa and found that cross-regional mergers and acquisitions can promote regional industrial upgrading and regional economic growth [17]. By establishing complex inter-regional $\mathrm{M} \&$ A networks and using social network analysis methods to study regional differences in cross-regional M \& As in China, Wile et al. (2012) think that cross-regional M \& As have obvious geographical differences and cross-regional $\mathrm{M} \&$ As are more concentrated in China's economically developed areas, while the backward areas are relatively small, and suggested that our country from a macro point of view of corporate mergers and acquisitions in order to facilitate the balanced development of industries in various regions, thereby promoting the optimization and upgrading of China's industrial structure [18].

\section{Literature Review and Prospect}

Through summarizing and summarizing the existing literature, we find that the conceptual definition and measurement of industrial upgrading can be based on two aspects of industrial structure and global value chain. The research is abundant only from a single aspect but generally lack of both the combination between. The industrial upgrading under the industrial structure mainly relied on macro data, focusing only on the analysis of the industry level, ignoring the influence of the enterprise level; whereas the value chain is just the opposite, only the industrial upgrading was studied from the micro perspective. Take the garment industry as an example, garment production is often ranked as a low-end industry, and its structural design stage before manufacturing is a high value-added segment upstream of the value chain. If only considering industrial upgrading from the perspective of industrial structure, it may cause managers to make erroneous industrial upgrading decisions, which is detrimental to the long-term development of the company. Therefore, the follow-up study can combine the theory of industrial structure and value chain theory, and use the macro data and micro data to comprehensively analyze the issue of industrial upgrading overall, providing the theoretical basis for enterprises to make the correct industrial upgrading decision.

With the increasing effect of $M$ \& $A$ on industrial upgrading, the research on both is gradually increasing. However, the main focus is on cross-border $M \& A$ and cross-border $M \& A$, and most of them are analyzed from a macro perspective. Research is not broad enough. M \& A and restructuring the upgraded relationship still has a lot of research space. First, we can combine micro-analysis with macro-industry structure analysis to fundamentally understand the mechanism and the correct approach of industrial upgrading. Generally speaking, the industry is at the macroscopic level, based on the perspective of a country or a certain region, and lacks understanding from a business perspective. Enterprises are just the foundation of a national industry. Numerous enterprises constitute different industries, and industrial upgrading is based on the value chain the understanding of angles is the increase of added value and technological content of the company's products. Therefore, the study of mergers and acquisitions and industrial upgrading can be combined with 
technological upgrading of enterprises, management mode improvement and related financial indicators, a comprehensive analysis of the relationship between the two, to maximize the merger and reorganization to promote industrial upgrading. Secondly, by joining in the factors of industrial upgrading and $\mathrm{M} \& \mathrm{~A}$ and restructuring, such as technological innovation, level of financial development, government intervention and intellectual property protection, we should explore the path and tactics of industrial upgrading by exploring the interrelation among the three, the optimization and upgrading of industrial structure will lead to economic transformation and growth.

\section{Acknowledgements}

Fund Project 1. 2017 Basic Research Projects of Higher Education Institutions in Liaoning Province "Institutional Environment, Cross-regional M\&A and Industrial Upgrading Effect" (2017J067).

Liaoning Education Department 2016 Connotation Development of Higher Education-Transformation and Innovation and Entrepreneurship Education Project "Innovation and Entrepreneurship Education Reform Pilot Program: Business Administration”.

\section{References}

[1]. Knout, B. Designing Global Strategies: Comparative and Competitive Value Added chains. Sloan Management Review. Vol. 26(1985) No. 4, p.15-28.

[2]. Giraffe G. International Trade and Industrial Upgrading in the Apparel Commodity Chain. Journal of International Economics. Vol. 48(1999) No. 1, p.564-698.

[3]. Poon T S C. Beyond the Global Production Networks: A Case of further Upgrading of Taiwan's Information Technology Industry. Technology and Globalization. Vol. 26 (2004) No. 1, p.130-145.

[4]. Bolin Wang. Industrial upgrading is a top priority for the development of labor-intensive industries in coastal areas. Economic Perspectives. (2009) No. 02, p.32-36.

[5]. Shaun Feng. Xing Kang. Wei Chen. Intellectual Property Management, Industrial Upgrading and Green Growth-A Case in Guangdong in the Process of Industrial Transformation and Upgrading. Forum on Science and Technology in China. (2016) No. 1, p.118-123.

[6]. Xenia Bay. Jingling Wei. Inter-Province Mergers, Inter-Regional Resources Flow and Industrial Upgrading: An Empirical Study Based on Chinese Data. Contemporary Finance \& Economics. (2017) No. 1, p.100-109.

[7]. Rife Huang. Xiao Hong Chen. FDI and Industrial Structure Upgrading: Theoretical and Empirical Research Based on Central Region. Management World. (2007) No. 3, p.154-155.

[8]. Yan Li. Empirical Analysis of Upgrade the Manufacturing Industry in Guangdong-Base on Dynamic Shift-Share Method. Techno economics \& Management Research. (2009) No. 3, p.106-109.

[9]. Lego Wang. Wash Zhao. Research on China's Financial Development and Industrial Structure Upgrading. Research on Financial and Economic Issues. (2015) No.1, p.22-29.

[10]. Xiao and Zhou. Men Gao. Wenham He. Financial Development, Industrial Structure, Capital Allocation Efficiency. Journal of Central University of Finance \& Economics. (2015) No.5, p.38-45.

[11]. Dong Yan. Nengjun Chen. Research on the Relationship between Financial Development, Trade Opening-up and Industrial Upgrading - Based on the Experience Data of China from 1999 to 2014. Inquiry into Economic Issues. (2016) No.8, p.36-43. 
[12]. Jingling Wei. Promotion of M\&A of State-owned Enterprises on Industrial Upgrading - Based on the Investigation of the Types of Ownership of Target Enterprises. Enterprise Economy (2017) No. 4, p.40-46.

[13]. Shaun Feng. Wei Chen. Intellectual Property Protection, Technological Innovation Performance and Industry Upgrading in Chinese Manufacturing-Based on Panel Data of 29 Manufacturing Industries. Reformation \& Strategy. (2015) No.5, p.138-142.

[14]. Eduardo Pablo. Determinants of cross-border MAs in Latin America. Journal of Business Research. (2009) No.62, p.861-867.

[15]. Deified N. Love J. H. Menghinello S. The Multinational Enterprise as a Source of International Knowledge Flows: Direct Evidence from Italy. Journal of International Business Studies. Vol. 41 (2010) No. 2, p.350-359.

[16]. Dunning J. H. The Eclectic Paradigm of International Production: A Restatement and Some Possible Extensions. Journal of International Business Studies. Vol. 19 (1988) No. 1, p.1-31.

[17]. Jew Hu. Squishing Zhang. Liang Hu. A Research on Regional Industry Integration and Regional Economy Growth: A Perspective of Trans-regional Merging. China Soft Science. (2012) No. 6, p.167-174.

[18]. Le Wei. Squishing Zhang. Laban Zhao. Industrial Restructuring and Transferring based on Complex Networks of CRMAs. Economic Geography. (2012) No. 2, p.89-93. 